\title{
El derecho a la salud, un tema presente
}

The right to health, a present issue

\author{
Daniela Carrasco Zúñiga,* Miguel Ángel Lezana Fernández,* \\ Fernando Meneses González*
}

Un eje esencial en la vida democrática de una nación es la protección a la salud de su población. En México, éste se encuentra consagrado en el artículo $4^{\circ}$ constitucional, el cual obliga a que el Estado brinde las garantías necesarias para el ejercicio efectivo de ese derecho fundamental que la población posee. La discusión del derecho a la protección de la condición saludable está presente de manera constante, es por ello que en el presente número se aborda bajo la óptica de Illán y Hernández, donde, desde la perspectiva de los derechos humanos, ellos consideran que los elementos que dan base al derecho a la sanidad son cuatro: la disponibilidad, la accesibilidad, la aceptabilidad y la calidad de los servicios y la atención en salud.?

En la conservación de la salud interactúan un profesional de la disciplina y una persona en busca de una solución a algún problema, interacción que ocurre en alguna institución de salubridad o en el consultorio médico; uno de los componentes que sirve de puente y enlace entre profesional y paciente es el expediente clínico. Dicho conjunto de información personal de un enfermo requiere de un manejo adecuado, confidencial y veraz, sobre la integración adecuada del expediente clínico que incluye, a través del consentimiento informado, la información de los riesgos por procedimiento e intervenciones realizadas a los pacientes. Ismael Garduza presenta un caso de medicina legal en el cual se muestra la importancia de la estructura correcta del expediente clínico y la implicación de la utilización inadecuada del mismo. Sirva este artículo a manera de ejercicio de enseñanza para aquellos jóvenes profesionales de la salud quienes inician sus carreras, y allí vean la importancia de estos instrumentos. ${ }^{2}$

El profesional de enfermería es un pilar para mantener la salud del paciente, en la manutención de la condición saludable del enfermo, las actividades específicas que ellos realizan son importantes en el manejo diario, procurando la prevención de complicaciones, al igual que los estándares específicos que se tienen a fin de evitarlas en tales pacientes durante su estancia hospitalaria, como lo exponen Moncada Heredia y sus colaboradores, en el reporte de caso del cuidado enfermero en úlcera por presión en un paciente crítico. ${ }^{3}$

A la importancia de la asistencia por parte de enfermería y doctores se suman las intervenciones del núcleo familiar, sobre todo en pacientes con enfermedades crónicas no transmisibles, esta última red de apoyo genera un impacto positivo en el control de estos padecimientos, se relaciona con una mejor respuesta al tratamiento debido al apego al mismo, mencionado en el trabajo Funcionalidad familiar en la adherencia terapéutica del paciente con hipertensión arterial sistémica en primer nivel de atención de Becerra y Villegas. ${ }^{4}$

* Dirección General de Difusión e Investigación. Comisión Nacional de Arbitraje Médico. México.

\section{Correspondencia:}

DCZ, dcarrasco@ conamed.gob.mx Conflicto de intereses: Los autores declaran no tener conflicto de intereses.

Citar como: Carrasco ZD, Lezana FMÁ, Meneses GF. El derecho a la salud, un tema presente. Rev CONAMED. 2027; 26(2): 55-56. https://dx.doi. org/10.35366/100347 Financiamiento: No hubo financiamiento. 
La actual pandemia por COVID-19 ha puesto de manifiesto la necesidad de insumos y equipos para el buen funcionamiento de las instituciones de salud pública, además de los profesionales de esa área quienes brindan atenciones y cuidados a los pacientes que atraviesan por esta enfermedad. Páez Moreno ${ }^{5}$ realiza una reflexión en torno a la relación de la COVID-19 con la ausencia de justicia social en nuestro país, así como la concepción de ser médico en la pandemia, desde el enfoque descrito por García Solís. ${ }^{6}$

Atenciones y custodia por familiares y profesionales de la salud, instalaciones, insumos y servicios que proporcionen al paciente la protección requerida en el transcurso de su enfermedad, son elementos que necesitan funcionar de manera sincrónica en el fortalecimiento del derecho al óptimo estado de bienestar de los mexicanos.

\section{REFERENCIAS}

1. Illán ME, Hernández MC. El derecho a la salud es un derecho humano. Rev CONAMED. 2027; 26 (2): 89-94.

2. García GI. Mala práctica médica. Caso médico-legal y dictamen. Rev CONAMED. 2021; 26 (2): 68-81.

3. Moncada HS, Luna PD, Lezana FMÁ, González VMS, Meneses GF. Calidad del cuidado enfermero. Úlcera por presión en paciente crítico. Rev CONAMED. 2021; 26 (2): 82-88.

4. Becerra PEN, Villegas CC. Funcionalidad familiar en la adherencia terapéutica del paciente con hipertensión arterial sistémica en primer nivel de atención. Rev CONAMED. 2027; 26 (2): 57-67.

5. Páez MR. COVID-19 en un país sin justicia social. Rev CONAMED. 2021; 26 (2): 101-103.

6. Carcía SE. Ser médico en la pandemia. Rev CONAMED. 2021; 26 (2): 95-97.

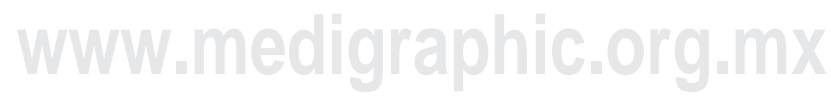

